\title{
Loaded both ways: The impact of dialectical tensions on nurses' manual handling practices
}

\author{
Kate Kay, Nel Glass, Alicia Evans \\ School of Nursing, Midwifery \& Paramedicine, Faculty of Health Sciences, Australian Catholic University, Fitzroy Vic, \\ Australia.
}

Correspondence: Kate Kay. Address: Faculty of Health Sciences, School of Nursing, Midwifery \& Paramedicine, The Daniel Mannix Building, 17 Young Street, Fitzroy Vic 3065 Locked Bag 4115, Fitzroy, MDC, VIC 3065, Australia. Email: kathryn.kay@optusnet.com.au

Received: October 10, 2013

DOI : $10.5430 /$ jnep.v4n1p218

Accepted: November 13, 2013 Online Published: December 9, 2013

URL: http://dx.doi.org/10.5430/jnep.v4n1p218

\section{Abstract}

Background: Manual handling is an integral part of the work of nursing however high injury rates persist. A clarification of the clinical practice issues related to manual handling is the first step towards reducing manual handling injuries. As historical, cultural and socio-political factors combine to shape nurses' manual handling practices, it is vital that the dominant paradigms guiding manual handling interventions are critically analysed. If the complexities of the clinical environment are not considered during the development of manual handling safety programs, then injuries and deviations from recommended practices may continue.

Methods: This paper discusses the findings from a qualitative research study conducted in 2012 on the manual handling experiences of thirteen nurses from two Australian states. The study explored nurses' perceptions and experiences relating to manual handling in the healthcare context and their participation in injury prevention programs. The research was framed in a critical emancipatory methodology incorporating an intent to provide opportunities for reflective practice, enhanced awareness and the potential for empowerment. The two methods used in this study were semi-structured interviews and researcher reflective journaling.

Findings: Thematic analysis produced an overarching theme of 'power relations' that revealed a subcategory of '(mis)power' and further subthemes of 'how to practice' and 'voicing practice issues'. Specifically this paper discusses a dataset on the first subtheme, 'how to practice' and the dialectical tensions experienced by nurses when undertaking manual handling activities. The findings suggest that the socio-political context of healthcare impacts upon nurses' professional lives and produces discordance between manual handling policy and practice. The authors argue that manual handling issues may not be resolved without due consideration of these contextual influences on practice.

Conclusion: Critical reflection and recognition of nurses' manual handling concerns can validate nurses' experiences and make explicit previously taken-for-granted assumptions about manual handling. A clear understanding of the conditions that constrain nursing practice is a prerequisite for manual handling improvements in healthcare. The inclusion of nurses' perspectives and experiences enables the generation of new insights to aid the development of interventions that are more readily embraced by clinicians. Furthermore, the reconceptualisation and identification of ways to restructure manual handling can empower nurses to act on the basis of this knowledge. The paper concludes with a discussion on the overall significance of conducting this study in relation to the development of sustainable manual handling practice changes within the existing healthcare context. 


\section{Key words}

Critical methodology, Dialectical tension, Emancipatory, Manual handling, Musculoskeletal disorders, Nursing practice, Power relations

\section{I ntroduction}

This paper presents a dataset from a recent qualitative study on nurses' manual handling experiences in healthcare organisations. A critical, emancipatory analysis of the manual handling issues faced by participants in their daily practice is offered. Whilst numerous evaluation studies of specific manual handling programs are reported in the literature, research on nurses' experiences and beliefs has been confined to injured clinicians or prevailing attitudes towards intervention programs or assistive equipment ${ }^{[1-9]}$. The current study illuminates the importance of applying knowledge arising from nurses' experiences to the development of manual handling injury prevention strategies in the healthcare sector.

To begin, background literature is introduced and provides an overview of the context for manual handling, inclusive of the historical marginalisation of nurses in the management of manual handling issues. Following this is a discussion of the data associated with power relations as demonstrated by the conflicts that confront nurses in regard to manual handling demands in their workplaces.

\subsection{Manual handling}

Manual handling is variously defined in current national and international manual handling regulatory documents as the actions required to handle, lift or move objects or people ${ }^{[10-14]}$. The provision of direct care to patients includes multiple manual handling actions and has resulted in high injury rates amongst nurses and other clinicians ${ }^{[15-19]}$. Despite research conducted over many years, issues pertaining to manual handling injuries arising from patient care episodes remain unresolved.

\subsection{I njuries from manual handling}

Musculoskeletal disorders (MSDs) consist of a variety of injury types arising from manual handling activities. As the aetiology of MSDs is multifactorial, it is difficult to directly identify the predictors for injury in any individual case. Consequently, injury prevention strategies are not easily constructed in the absence of proven risk factors ${ }^{[20,21]}$. Furthermore, the development of a MSD may be in response to a single injury event or the result of cumulative trauma over time ${ }^{[13]}$. Whilst a causal relationship between manual handling and MSDs has been indicated in previous research studies, methodological heterogeneity has hindered direct comparisons across studies. Hence the identification of elements crucial to consistent injury prevention has remained elusive ${ }^{[22-24]}$. A flotilla of ergonomic guidelines and policies intended to counter manual handling issues have produced only partial success to date ${ }^{[4,12,13,25]}$.

\subsection{MSD prevalence in healthcare}

The uncertainty regarding MSD detection and diagnosis can result in underestimates of injury rates however the high prevalence of MSDs within healthcare has been noted for some time ${ }^{[26-28]}$. The seminal review by Buckle ${ }^{[29]}$ identified that nurses' lifetime back injury rates were estimated to be between $35 \%$ and $80 \%$. International studies have since replicated these findings as have a variety of robust cross-sectional studies throughout Australia ${ }^{[30-32]}$.

\subsection{Marginalisation of nurses' manual handling experiences}

The manual handling workload for nurses has increased as a result of changes in the structure of healthcare over the past century, yet the potential impact upon nurses was largely overlooked until MSD symptoms appeared ${ }^{[33-35]}$. For many years nurses were trained in 'body mechanics' despite the lack of supportive evidence for this approach ${ }^{[4,19,34]}$. Educational approaches based on the medical model have dominated injury prevention programs and included, at best, only minimal input from nurses ${ }^{[23,36]}$. Hence important contextual influences on nurses' manual handling practices have generally been 
disregarded $^{[25,33]}$. The historical subordination of nurses' manual handling experiences highlights the need to explore nurses' perspectives and foreground any socio-political influences previously overlooked.

\subsection{Research overview}

This paper reports a dataset from a qualitative research study designed to explore nurses' experiences of manual handling and their perspectives on injury prevention programs in healthcare organisations.

\section{Methods}

\subsection{Research design}

The aim of this research was to explore clinical practice issues related to manual handling. An enhanced understanding of the clinical context can inform the development of intervention strategies better suited to nursing care in the healthcare environment. The insights gained from this study contribute to the advancement of occupational safety for nurses.

A critical emancipatory methodology was chosen. Explicitly this study was intended to generate knowledge that has the potential for nurses' emancipation from relevant oppressive structures within the healthcare environment ${ }^{[37-40]}$. Consistent with qualitative epistemology and the aim to explore human knowledge, semi-structured interviews and researcher reflective journaling were selected as the methods for this study ${ }^{[41]}$. Critical realism was also incorporated into the research design and has been used by scholars previously to investigate practice issues within the complex social healthcare system ${ }^{[42]}$. Critical realism acknowledges the social dimensions of knowledge and the influence of context on outcomes ${ }^{[43-46]}$. A critical realist lens allowed the exploration of structural factors and generative mechanisms that influence nurses' manual handling practices.

\subsubsection{Research questions}

The research questions were:

1) What are the beliefs, attitudes and experiences of nurses pertaining to manual handling?

2) How do nurses perceive their knowledge of manual handling and safe practices is received by other health care professionals?

3) How can nurses' knowledge of manual handling be incorporated into the development of interventions to reduce injuries?

\subsubsection{Ethical considerations}

Institutional ethics approval was obtained prior to the recruitment of participants and data collection activities. Aligned with the view that research ethics comprises an ongoing, dynamic process rather than an simply an administrative formality, the researcher maintained a focus on research merit, respect, justice and beneficence throughout the study ${ }^{[47]}$. Informed consent was obtained from participants in writing initially and then renegotiated whenever required throughout the study.

\subsection{Data collection and analysis}

Notices in professional journals, announcements at professional conferences and snowball referrals were all used to inform potential participants about the study. Thirteen registered nurses volunteered to participate in semi-structured interviews in 2012. The participants were employed in acute or aged care facilities across the Australian states of Victoria and Tasmania. The participants' ages ranged between 25 and 64 years of age and five had attained their nursing qualifications in undergraduate university nursing programs. The remainder of participants had gained pre-registration certificate-based nursing qualifications. All interviews were undertaken at a location chosen by the participant. 
Researcher reflective journaling was the second method used in the current study. This method is frequently incorporated into critical research designs to promote researcher reflexivity and ensure transparency of process ${ }^{[48-50]}$. Reflection on the researcher's own assumptions enables a reflexive analysis of the entire research process, enhancing the rigour and credibility of the study ${ }^{[51]}$.

A modified version of Braun and Clarke's ${ }^{[52]}$ thematic analysis was utilised as the framework for data analysis and the details have been published elsewhere ${ }^{[53]}$. The first stage for this study entailed familiarisation with the data by repeated listening to the interview recordings and critical review of the researcher's journal entries. Full transcription then followed to confirm or reject the key aspects identified during auditory analysis. Data analysis entailed a dynamic and iterative process of moving back and forward between stages of analysis and re-examination of other interviews as key aspects emerged. A critical realism lens was used to examine the data and further integrated the tenets of critical social science.

Congruent with the critical paradigm, data analysis included aspects of the interviews beyond the spoken word that were analysed as possible indicators of marginalisation ${ }^{[48]}$. Silences, pauses, body language, gestures and facial expressions were noted and later analysed in conjunction with the specific thoughts and feelings articulated by participants ${ }^{[54]}$.

\section{Rigour of analysis}

Deep immersion in the audio recordings of interviews allowed the first author to identify key aspects of the data. These features were subsequently confirmed by the independent review of six interviews undertaken by the co-investigators. Reflexivity was used throughout all phases of the study ${ }^{[55]}$. As part of the iterative process, all participants were offered a copy of their interview to enable member checking and additional review occurred when three participants attended a presentation of the preliminary findings at a national conference.

\section{Findings}

The key findings from the study were associated with issues of 'power relations'. Whilst the participants did not explicitly state they were oppressed, the issue of power relations was threaded through their interviews. As one participant stated, “... you're told what to do and that's what you do... there will be no negotiation! You won't ask questions ... and that's it!" '(Mis)power' was identified as a subcategory of 'power relations' during the critical analysis of verbal and non-verbal data. '(Mis)power' was exemplified in participants' narratives, particularly in their expressions of anger, frustration, scepticism or disillusionment in relation to manual handling issues. Two subthemes of '(mis)power' emerged from the data, these being 'voicing practice issues' and 'how to practice'. This paper discusses the latter subtheme in terms of the tensions experienced by nurses within themselves and with others.

'(Mis)power' was coined to represent the inappropriate, negative power, or negative use of power as perceived by participants, explicitly or implicitly, in relation to responses to manual handling issues. In this study, a misappropriation, misuse or misdirection of power was revealed in relation to manual handling practices and intervention programs. For instance, several participants identified that injury prevention programs did not transfer effectively into clinical settings yet they were expected to employ strategies they found problematic. One participant explained that "... if what they recommended was always practical, then yeah, it would work. Then you'd do it. But sometimes it's just not practical." Participants also discussed the exclusion of nurses from the manual handling dialogue and their own perceptions of manual handling mismanagement.

\subsection{Dialectical tensions}

Dialectical tensions can be viewed as the tensions created in the negotiation of coexisting opposing phenomena or forces ${ }^{[56,57]}$. Dialectical tensions can be examined in terms of a struggle between competing forces that propels an individual towards either of the contradictory yet interdependent polarities ${ }^{[58]}$. The tensions may be present intrapersonally within an individual, or alternatively interpersonally in the social and professional environment. 


\subsubsection{I ntrapersonal dialectical tensions}

Participants experienced internal conflict when they perceived that a focus on their own wellbeing may compromise patient care. The view that patients' needs are paramount was evidenced by Alex's declaration regarding the prioritisation by nursing staff of patient care above manual handling risks to themselves:

No, the resident first. I always put the patient first. [laughs]. I know I shouldn't [put the patient's welfare above my wellbeing],... nurses never, ever, consider [themselves]...

Quinn explained the internal dilemma she experienced when patients expected manual assistance. Despite concerns for her own safety, the primacy of patient needs appeared to override personal risk:

... if you turn around and say to a patient "Well I can’t do that” you then feel guilty because you're not helping them or you're not doing what's best for them ... I don't feel guilty saying I'm not going to lift that tray because it's not impacting on the tray. Yeah! But ... to say [to a patient] "Well I'm not going to help you up the bed, you can do that yourself.”... [makes me feel a] sort of guilt ... This is my role as a nurse to be caring for you. [If] you can't do it, or you don't want to do it ... [then] I'm being selfish here saying "No I won't do it [for you].” [But] I want to protect myself! It's guilt and selfish ... So you'll put yourself at risk to care for the patient.

Additionally, some participants noticed contradictions between their verbalised beliefs regarding self-care, and instances of their own deviations from safe practice guidelines. Alex noted this and suggested that an absence of assistive equipment, a wish to avoid the negative judgements of colleagues and perceived time pressures might explain her own actions:

... we, [pause] are trying to manage time [emphasis in louder voice], ... you don't want someone else to think you're slack because you didn't [carry supplies manually] [laughs]... Well, I tell you what, if someone was bringing me [supplies]... and carrying it, I would tell them off. [Laughs again]. I just listened to myself! Yeah. I would. I would! I would actually go crook. I would actually say "Put that box down, go and find a trolley ... do not carry it!” But you know, I'd do it [carry the box]. Yeah.... Isn’t that strange? [pauses and laughs]... Because I would do it. I would! I would [pause] carry it, yeah, but I wouldn’t want anyone else to.

\subsubsection{Professional and interpersonal dialectical tensions}

A disharmony between colleagues was reported consequent to differing beliefs about the need to follow manual handling policies. Quinn felt frustrated about the futility of teaching colleagues safe practices that weren't utilised. Her comments revealed inconsistencies between the priorities stated in policies and perceived time pressures that hindered injury prevention strategies in practice:

... It's like 'I can do it, and somebody's watching me and I'm being assessed... But I won't put it into my everyday practice.' ... and you've got people saying “Just do it quickly [not the recommended way]” ... they won’t [follow recommended practices] because it takes too long.

Some participants admitted that their desire to maintain harmonious relationships with colleagues overruled their intentions to follow injury prevention strategies. Scepticism regarding the need to follow safe handling recommendations was sometimes presented as an explanation for the decision to deviate from policy:

... I'm a little bit guilty of that too... instead of using the slide sheets we use the 'mac' [waterproof drawsheets] as a slide sheet. It actually does work... It's actually a lot quicker and ... it feels like it's less handling because you're not rolling the patient, you know, 20 times to get the slide sheet in. And if you tilt the bed...it's actually a lot easier than the initial rolling to get them on the slide sheet to begin with. 
The expectation to follow mandated manual handling policies was juxtaposed with the perceived inappropriateness of strategies for clinical settings. Pat's colleagues frequently disregarded manual handling policies but were careful to avoid detection. Pat averted her gaze from the researcher and lowered her voice before disclosing:

I know it's bad... it's not following the correct techniques and policies and procedures .... and all the education and everything that they've done and we still go against it. It's bad, I know it's bad... It's kind of a 'don't ask, don't tell' ... So we do our own thing ... whereas if we get [external staff or] ... if we have students ... it's kind of 'Well, we'll do the right thing'. So we'll teach [others] the right way, but we won't follow it ... we want to look like we're doing the right things so we don't get reported.

Interpersonal tensions were further highlighted by managerial decisions that discounted nurses' concerns regarding manual handling risks and failed to adequately address these issues. Chris felt "devalued" after a specific manual handling issue was not investigated thoroughly and Jamie was frustrated by management decisions that hindered easy access to specific manual handling information:

...[we] wanted the manual handling charts out on the door, and we were told "No". ...We said that we want them and she said "You can't have them”. So it wasn’t really a negotiation.

Whilst participants approved, in principle, of formal efforts to enhance manual handling safety, they were ambivalent about the true intentions of their employers and expressed discontent about organisational choices for injury prevention. When asked about the reasons for manual handling policies in the workplace, Quinn declared:

Do you want my cynical reasons [for the policy]? ... Okay. I think a lot of it is to cover the hospital so that if they do get someone who's injured, it's like "Oh, we had a policy and you should have done this” ... But it often gets overlooked if you don't [follow policy] ... Nobody gets pulled up on not doing it correctly. And that's coming from the top [of the organisation], down.

Participants were hesitant to report their manual handling injuries, fearing negative repercussions despite formal policies detailing mandatory reporting. Fears included threats to employment security, feeling blamed for the injury event and stigmatisation. Monitoring of injuries, overtly presented as a mechanism to enhance understanding of manual handling issues, was viewed by participants as an opportunity to apportion blame. Injured nurses were also perceived as a burden to their employers:

... they [administrators] look at it from a cost point of view. So it's like 'if you get injured we have to pay for you and if you can't work we have to pay for a replacement.' You know, and it's like, almost a guilt thing. ... if someone was to get injured, ... I don't know a lot of people who would say ... "I got injured doing this" because of the stigma ... They would've been injured by poor manual handling... but they might not say that that's what's happened, because of the stigma...

The comment above suggested that poor manual handling technique was the cause of injuries, rather than contextual impediments to safety. The anticipated stigmatisation of injured nurses discouraged injury reporting despite policies stipulating mandatory reporting.

Confusion was evident with regard to the changing nature of practice recommendations over time with guidelines viewed as transient, unreliable and far from definitive. Jessie disagreed with several current manual handling recommendations, illustrating her confusion about 'how to practice':

What might have been right a couple of years ago, they've decided now isn't... Like the 'pinkies' [waterabsorbing drawsheets]... they're going to do away with those, we've heard. Because people lift [using the 
drawsheet instead of assistive devices]. But in certain patients there's nothing wrong with lifting them [using the drawsheet]! In my opinion, a small patient and they just need to go up the bed a little bit...

Most participants doubted the efficacy of injury prevention strategies and Quinn was particularly perplexed at the continued promotion of a program that appeared to be ineffective. This further perpetuated the internal tensions for Quinn as the additional efforts required to conform to manual handling policies were not viewed as beneficial:

... at the last training we went to, it was a lot of "This is what it costs us if you're off sick. These are how many people were off injured. This is how much it costs the organisation.” ... it was just like... 'Yeah, we're teaching you this program. And the program itself doesn’t work' ...They were presenting it as 'It doesn't work'.

\section{Discussion}

Manual handling tasks related to patient care requirements have generated high injury rates within the nursing profession and injury prevention programs have had limited success. There is at best equivocal evidence for contemporary injury prevention strategies to reduce MSDs ${ }^{[22,59,60]}$. A systematic review highlighted the need to examine barriers and facilitators for the implementation of intervention programs, noting the complex interplay of systemic, individual and

socio-political factors ${ }^{[24]}$. In addition, Kearney and Lever ${ }^{[61]}$ suggested that nursing work is taken-for-granted, invisible and fundamentally undervalued and Clarke ${ }^{[62]}$ similarly identified a limited understanding of nursing practice and the significance of contextual factors.

The marginalisation of nurses and their general exclusion from the development of manual handling programs has directed attention towards particular types of risk factors, at the expense of others. For instance, there has been a focus on the use of lifting equipment that requires considerable effort to push and manoeuvre, particularly on carpeted floors or where space is limited. This narrow focus on biomechanical equipment may derail injury reduction efforts by neglecting the socio-political constraints that influence manual handling practices ${ }^{[63]}$. Scholars have recently posited that the empowerment of nurses, by inclusion in program development and selection, would facilitate manual handling safety in healthcare ${ }^{[4,9]}$.

The intentions of the current study were: to foreground nurses' manual handling perspectives, provide opportunities for new insights that could further nurses' manual handling safety and through verbalising their experiences, facilitate possible empowerment of participants after reflection on their manual handling circumstances.

The participants' narratives unveiled the dialectical tensions experienced by these nurses during their attempts to assimilate recommended practices for manual handling safety in the face of conflicting personal, clinical and organisational demands. Such conflicts may explain the mixed results from manual handling intervention programs reported in the literature.

Conflicts between colleagues were also noted in the current study when individuals attempted to continue using outdated manual handling practices. Furthermore, participants' experiences of conflicting or evolving recommendations created confusion about how to practice. This generated an uncertainty that destabilised the participants' beliefs in the appropriateness of guidance advice, leading some to diverge from mandated actions for manual handling.

Numerous dialectical tensions were uncovered between self-protective behaviours for participants that were at odds with perceived productivity goals, expectations of colleagues and patient needs. Intrapersonal dialectical tensions were elicited in disclosures regarding the emotional conflict experienced by participants who felt guilty or uncomfortable when self-care contradicted the needs or expectations of patients. This concurs with the findings of research in other domains of 
nursing practice where tensions between policy ideals and the daily realities of nurses' working circumstances impacted upon decisions to comply with formalised policies ${ }^{[57]}$.

Furthermore, Flin ${ }^{[64]}$ noted that clinicians' perceptions of managerial commitment to safety policies had the potential to influence occupational safety practices in healthcare. In the current study, participants expressed frustration with managers who did not respond to violations of safe manual handling policies and the tensions this created in the workplace. This finding aligns well with similar reports in the safety literature for healthcare ${ }^{[65]}$.

The professed reticence of participants to formally report injuries demonstrated a specific dialectical tension between policy requirements and nursing practice. Perceived negative consequences, such as blame, stigmatisation and limited employment prospects hindered injury reporting. Scholars have previously noted the dialectical tension present for nurses when negative repercussions are anticipated ${ }^{[56]}$.

This paper shares the voices of the participating nurses, their manual handling experiences and their responses to their subjugated position in healthcare, specifically in relation to manual handling. The study foregrounds the marginalisation of the participants, their inner tensions and conflicts, powerlessness and emotional dilemmas and attempts to self-manage their circumstances.

The ability to voice manual handling concerns allowed participants the opportunity to create new meanings as a result of their reflections. Some participants became aware of inconsistencies between safe handling directives and the absence of resources in their workplaces, whilst others noticed contradictions between their stated intentions and personal practices. A proportion of participants in this study actively expressed plans to change, clarify or highlight previously unacknowledged issues when they returned to their clinical environments.

\section{Study strengths and limitations}

This study comprised in-depth interviews with 13 nurses who self-selected to participate, in combination with researcher reflective journaling. Reflection by the researcher promoted reflexivity throughout the study by foregrounding the researcher's preconceptions and therefore enabling transformation of the study in response to such insights ${ }^{[49]}$. Reflexivity endeavours to make transparent the researcher's assumptions thereby adding support for the credibility and rigour of the study.

It was not intended that the findings from this qualitative study would be generalisable to other nurses, however the findings may be valuable to future research studies. We have provided rich data on the participants' verbal and non-verbal responses to allow readers to determine for themselves the trustworthiness and relevance of our findings.

\section{Conclusion}

Manual handling is an integral part of the work of nursing however disproportionately high injury rates persist in comparison with other industries and occupations ${ }^{[4,16,66]}$. In order to increase awareness of the issues that nurses face in the clinical practice setting, nurses' manual handling experiences were explored and semi-structured interviews gave participants the opportunity to reflect on the socio-political constraints that influence manual handling practices. The perceived marginalisation of nurses was found to contribute to ongoing dialectical tensions experienced by participants and this has been identified previously by scholars investigating other domains of nursing practice ${ }^{[67,68]}$. The nurse participants in this study were typically excluded from decisions regarding organisational directives for safe practice yet required to implement recommendations that did not articulate well with the realities of clinical environments and organisational goals for the efficient delivery of patient care. 
An overarching theme of 'power relations', encompassing the theme '(mis)power' was identified in this study. The dataset related to the subtheme 'how to practice' has been discussed in relation to the multiple dialectical tensions experienced by participants during manual handling events. The new knowledge gained from this study may contribute to explanations for the ongoing high prevalence of MSDs in the nursing profession despite technical and ergonomic advances. The current study suggests that socio-political context is an important factor in the manual handling practices of nurses and cannot be disregarded without consequence.

Several years ago, a scholar questioned: "Why have we not solved the MSD problem?" ${ }^{[63]}$. The authors would argue that an understanding of the manual handling experiences and knowledge possessed by nurses forms a significant part of the answer and would substantially progress the occupational wellbeing of nurses.

\section{References}

[1] Andersen L, Burdorf A, Fallentin N, Persson R, Jakogsen M, Mortensen O, et al. Patient Transfers and Assistive Devices: Prospective Cohort Study for Occupational Back Injury among Healthcare Workers. Scand J Work Environ Health. 2013. http://dx.doi.org/10.5271/sjweh.3382

[2] Burdorf A, Koppelaar E, Evanoff B. Assessment of the Impact of Lifting Device Use on Low Back Pain and Musculoskeletal Injury Claims among Nurses. Occupational and Environmental Medicine. 2013; 70(7): 491-497. http://dx.doi.org/10.1136/oemed-2012-101210

[3] Engkvist I-L. Evaluation of an Intervention Comprising a No Lifting Policy in Australian Hospitals. Applied Ergonomics. 2006; 37(2): 141-148. PMid:16154108 http://dx.doi.org/10.1016/j.apergo.2005.05.008

[4] Garg A, Kapellusch JM. Long-Term Efficacy of an Ergonomics Program That Includes Patient-Handling Devices on Reducing Musculoskeletal Injuries to Nursing Personnel. Human Factors: The Journal of the Human Factors and Ergonomics Society. 2012; 54(4): 608-625. http://dx.doi.org/10.1177/0018720812438614

[5] Gropelli TMP, Corle K. Nurses' and Therapists' Experiences with Occupational Musculoskeletal Injuries. AAOHN Journal. 2010; 58(4): 159-166.

[6] Hignett S, Crumpton E, Ruszala S, Alexander P, Fray M, Fletcher B. Evidence-Based Patient Handling: Tasks, Equipment and Interventions. London: Routledge, 2003.

[7] Koppelaar E, Knibbe JJ, Miedema HS, Burdorf A. Individual and Organisational Determinants of Use of Ergonomic Devices in Healthcare. Occupational and Environmental Medicine. 2013; 68(9): 659-665. PMid:21098827 http://dx.doi.org/10.1136/oem.2010.055939

[8] Nelson A, Matz M, Chen F, Siddharthan K, Lloyd J, Fragala G. Development and Evaluation of a Multifaceted Ergonomics Program to Prevent Injuries Associated with Patient Handling Tasks. International Journal of Nursing Studies. 2006; 43(6): 717-733. PMid:16253260 http://dx.doi.org/10.1016/j.ijnurstu.2005.09.004

[9] Theis JL, Finkelstein MJ. Long-Term Effects of Safe Patient Handling Program on Staff Injuries. Rehabilitation Nursing. 2013: 1-9. http://dx.doi.org/10.1002/rnj.108

[10] ASCC. National Code of Practice for Prevention of Musculoskeletal Disorders Caused from Performing Manual Tasks. Canberra: Australian Safety and Compensation Council; 2007.

[11] Hignett S, Fray M, Rossi MA, Tamminen-Peter L, Hermann S, Lomi C, et al. Implementation of the Manual Handling Directive in the Healthcare Industry in the European Union for Patient Handling Tasks. International Journal of Industrial Ergonomics. 2007; 37(5): 415-423. http://dx.doi.org/10.1016/j.ergon.2007.01.003

[12] HSE. Manual Handling. Manual Handling Operations Regulations 1992 (as Amended): Guidance on Regulations. London: Health \& Safety Executive; 2004.

[13] Safe Work Australia. Hazardous Manual Tasks: Code of Practice. Canberra: Commonwealth of Australia; 2011.

[14] WorkSafe Victoria. Code of Practice for Manual Handling. Melbourne: Victorian Workcover Authority; 2007.

[15] ASCC. National Hazard Exposure Worker Surveillance (NHEWS) Survey. Canberra: Australian Safety and Compensation Council; 2009.

[16] Campo M, Weiser S, Koenig K, Nordin M. Work-Related Musculoskeletal Disorders in Physical Therapists: A Prospective Cohort Study with 1-Year Follow-Up. Physical Therapy. 2008; 88: 608-619. http://dx.doi.org/10.2522/ptj.20070127

[17] D’Arcy L, Sasai Y, Stearns S. Do Assistive Devices, Training, and Workload Affect Injury Incidence? Prevention Efforts by Nursing Homes and Back Injuries among Nursing Assistants. Journal of Advanced Nursing. 2012; 68(4): 836-845. http://dx.doi.org/10.1111/j.1365-2648.2011.05785.x 
[18] Holman G. Decision Factors in Patient Handling. In DS Bloswick, KT Hegmann, RF Sesek, eds. Fourth Annual Regional National Occupational Research Agenda (NORA) Young/New Investigators' Symposium. Salt Lake City, Utah; 2006: 51-65.

[19] Wardell H. Reduction of Injuries Associated with Patient Handling. AAOHN Journal. 2007; 55(10): 407-412. PMid:17969538

[20] Punnett L, Wegman D. Work-Related Musculoskeletal Disorders: The Epidemiologic Evidence and the Debate. Journal of Electromyography and Kinesiology. 2004; 14: 13-23. http://dx.doi.org/10.1016/j.jelekin.2003.09.015

[21] Yassi A, Lockhart K. Work-Relatedness of Low Back Pain in Nursing Personnel: A Systematic Review. International Journal of Occupational and Environmental Health. 2013; 19(3): 223-244. http://dx.doi.org/10.1179/2049396713Y.0000000027

[22] Martimo K-P, Verbeek J, Karppinen J, Furlan A, Takala E-S, Kuijer P, et al. Effect of Training and Lifting Equipment for Preventing Back Pain in Lifting and Handling: Systematic Review. bmj. 2008; 336(7641): 429-431. http://dx.doi.org/10.1136/bmj.39463.418380.BE

[23] Charney W, Hudson A, Gallagher S, Lloyd J, Baptiste A, Nelson A, et al. Back Injury Prevention in Health Care. In Handbook of Modern Hospital Safety (2nd ed.). Boca Raton: CRC Press, 2010, 1-125.

[24] Koppelaar E, Knibbe JJ, Miedema HS, Burdorf A. Determinants of Implementation of Primary Preventive Interventions on Patient Handling in Healthcare: A Systematic Review. Occupational and Environmental Medicine. 2009; 66(6): 353-360. http://dx.doi.org/10.1136/oem.2008.042481

[25] Koppelaar E, Knibbe JJ, Miedema HS, Burdorf A. The Influence of Individual and Organisational Factors on Nurses' Behaviour to Use Lifting Devices in Healthcare. Applied Ergonomics. 2013; 44(4): 532-537. PMid:23273749 http://dx.doi.org/10.1016/j.apergo.2012.11.005

[26] ASCC. Research on the Prevention of Work-Related Musculoskeletal Disorders. Canberra: Australian Safety and Compensation Council; 2006.

[27] Menzel NN. Underreporting of Musculoskeletal Disorders among Health Care Workers: Research Needs. AAOHN Journal. 2008; 56(12): 487-494. http://dx.doi.org/10.3928/08910162-20081201-06

[28] Safe Work Australia. Work-Related Injuries in Australia, 2005-06: Factors Affecting Applications for Workers' Compensation. Canberra: Commonwealth of Australia; 2009.

[29] Buckle P. Epidemiological Aspects of Back Pain within the Nursing Profession. International Journal of Nursing Studies. 1987; 24(4): 319-324. http://dx.doi.org/10.1016/0020-7489(87)90024-1

[30] Mitchell T, O'Sullivan PB, Burnett AF, Straker L, Rudd C. Low Back Pain Characteristics from Undergraduate Student to Working Nurse in Australia: A Cross-Sectional Survey. International Journal of Nursing Studies. 2008; 45(11): 1636-1644. PMid:18420208 http://dx.doi.org/10.1016/j.ijnurstu.2008.03.001

[31] Retsas A, Pinikahana J. Manual Handling Activities and Injuries among Nurses: An Australian Hospital Study. Journal of Advanced Nursing. 2000; 31(4): 875-883. http://dx.doi.org/10.1046/j.1365-2648.2000.01362.x

[32] Smith D, Leggat P. Musculoskeletal Disorders among Rural Australian Nursing Students. Australian Journal of Rural Health. 2004; 12: 241-245. PMid:15615575 http://dx.doi.org/10.1111/j.1440-1854.2004.00620.x

[33] Kay K, Glass N, Evans A. Reconceptualising Manual Handling: Foundations for Practice Change. Journal of Nursing Education \& Practice. 2012; 2(3): 203-212. http://dx.doi.org/10.5430/jnep.v2n3p203

[34] Collins J, Menzel N. Scope of the Problem. In Safe Patient Handling and Movement. A Nelson, ed. New York, NY: Springer, 2006, 3-26.

[35] Wall S. Critical Perspectives in the Study of Nursing Work. Journal of Health Organization and Management. 2010; 24(2): 145-166. http://dx.doi.org/http://dx.doi.org/10.1108/14777261011047327

[36] HSE. Manual Handling Training: Investigation of Current Practices and Development Guidelines. London: Health \& Safety Executive, 2007.

[37] Fay B. Critical Social Science: Liberation and Its Limits. New York: Cornell University Press, 1987.

[38] Roberts SJ, De Marco R, Griffin M. The Effect of Oppressed Group Behaviours on the Culture of the Nursing Workplace: A Review of the Evidence and Interventions for Change. Journal of Nursing Management. 2009; 17(3): 288-293. http://dx.doi.org/10.1111/j.1365-2834.2008.00959.x

[39] Rose J, Glass N. The Importance of Emancipatory Research to Contemporary Nursing Practice. Contemporary Nurse. 2008; 29(1): 8-22. http://dx.doi.org/10.5172/conu.673.29.1.8

[40] Taylor B. Qualitative Methodologies and Postmodern Influences. In Research in Nursing and Health Care: Evidence for Practice (3rd ed.). B Taylor, S Kermode, K Roberts, eds. Melbourne: Thomson, 2006, 362-392.

[41] Taylor B, Roberts K. Research in Nursing and Health. In Research in Nursing and Healthcare: Evidence for Practice (3rd ed.). B Taylor, S Kermode, K Roberts, eds. Melbourne: Thomson, 2006, 1-32.

[42] Wilson V, McCormack B. Critical Realism as Emancipatory Action: The Case for Realistic Evaluation in Practice Development. Nursing Philosophy. 2006; 7(1): 45-57. http://dx.doi.org/10.1111/j.1466-769X.2006.00248.x

[43] Angus JE, Clark A M. Using Critical Realism in Nursing and Health Research: Promise and Challenges. Nursing Inquiry. 2012; 19(1): 1-3. http://dx.doi.org/10.1111/j.1440-1800.2011.00580.x 
[44] Clark AM, Lissel S, Davis C. Complex Critical Realism: Tenets and Application in Nursing Research. Advances in Nursing Science. 2008; 31(4): E67-E79. http://dx.doi.org/10.1097/01.ANS.0000341421.34457.2a

[45] Parlour R, McCormack B. Blending Critical Realist and Emancipatory Practice Development Methodologies: Making Critical Realism Work in Nursing Research. Nursing Inquiry. 2012; 19(4): 308-321. http://dx.doi.org/10.1111/j.1440-1800.2011.00577.x

[46] Porter S, O’Halloran P. The Use and Limitation of Realistic Evaluation as a Tool for Evidence-Based Practice: A Critical Realist Perspective. Nursing Inquiry. 2012; 19(1): 18-28. http://dx.doi.org/10.1111/j.1440-1800.2011.00551.x

[47] National Statement on Ethical Conduct in Human Research. Canberra: The National Health and Medical Research Council; 2007.

[48] Holloway I, Biley F. Being a Qualitative Researcher. Qualitative Health Research. 2011; 21(7): 968-975. PMid:21266705 http://dx.doi.org/10.1177/1049732310395607

[49] Mantzoukas S. The Inclusion of Bias in Reflective and Reflexive Research. Journal of Research in Nursing. 2005; 10(3): $279-295$. http://dx.doi.org/10.1177/174498710501000305

[50] Rose J, Glass N. An Australian Investigation of Emotional Work, Emotional Wellbeing and Professional Practice: An Emancipatory Inquiry. Journal of Clinical Nursing. 2010; 19: 1405-1414. PMid:20500350 http://dx.doi.org/10.1111/j.1365-2702.2009.02997.x

[51] Reimer-Kirkham S, Anderson J. The Advocate-Analyst Dialectic in Critical and Post-Colonial Feminist Research: Reconciling Tensions around Scientific Integrity. Advances in Nursing Science. 2010; 33(3): 196-205. PMid:20693830 http://dx.doi.org/10.1097/ANS.0b013e3181e4a7d3

[52] Braun V, Clarke V. Using Thematic Analysis in Psychology. Qualitative Research in Psychology. 2006; 3(2): 77-101. http://dx.doi.org/10.1191/1478088706qp063oa

[53] Kay K, Evans A, Glass N. Moments of Speaking and Silencing: Nurses Share Their Experiences of Manual Handling in Healthcare. Collegian. 2013. http://dx.doi.org/10.1016/j.colegn.2013.11.005

[54] Ezzy D. Qualitative Interviewing as an Embodied Emotional Performance. Qualitative Inquiry. 2010; 16(3): 163-170. http://dx.doi.org/10.1177/1077800409351970

[55] Kitto S, Chesters J, Grbich C. Quality in Qualitative Research. Medical Journal of Australia. 2008; $188(4)$ : $243-246$. PMid:18279135

[56] Apker J, Propp KM, Zabava Ford WS. Negotiating Status and Identity Tensions in Healthcare Team Interactions: An Exploration of Nurse Role Dialectics. Journal of Applied Communication Research. 2005; 33(2): 93-115. http://dx.doi.org/10.1080/00909880500044620

[57] Orbe MP, King G. Negotiating the Tension between Policy and Reality: Exploring Nurses' Communication About Organizational Wrongdoing. Health Communication. 2000; 12(1): 41-61. http://dx.doi.org/10.1207/s15327027hc1201_03

[58] Levy-Storms L, Claver M, Gutierrez V, Curry L. Individualized Care in Practice: Communication Strategies of Nursing Aides and Residents in Nursing Homes. Journal of Applied Communication Research. 2011; 39(3): 271-289. http://dx.doi.org/10.1080/00909882.2011.585400

[59] Dawson AP, McLennan SN, Schiller SD, Jull GA, Hodges PW, Stewart S. Interventions to Prevent Back Pain and Back Injury in Nurses: A Systematic Review. Occupational and Environmental Medicine. 2007; 64(10): 642-650. http://dx.doi.org/10.1136/oem.2006.030643

[60] Verbeek J, Martimo K, Karppinen J, Kuijer P, Viikari-Juntura E, Takala EP. Manual Material Handling Advice and Assistive Devices for Preventing and Treating Back Pain in Workers. Cochrane Database Syst Rev. 2011; 15: CD005958.

[61] Kearney PM, Lever S. Rehabilitation Nursing: Invisible and Underappreciated Therapy. International Journal of Therapy \& Rehabilitation. 2010; 17(8): 394-395.

[62] Clarke DJ. Nursing Practice in Stroke Rehabilitation: Systematic Review and Meta-Ethnography. Journal of Clinical Nursing. 2013. http://dx.doi.org/10.1111/jocn.12334

[63] Wells R. Why Have We Not Solved the MSD Problem? Work: A Journal of Prevention, Assessment and Rehabilitation. 2009; 34(1): 117-121. http://dx.doi.org/10.3233/wor-2009-0937

[64] Flin R. Measuring Safety Culture in Healthcare: A Case for Accurate Diagnosis. Safety science. 2007; 45: $653-667$. http://dx.doi.org/10.1016/j.ssci.2007.04.003

[65] Hale A, Borys D. Working to Rule, or Working Safely? Part 1: A State of the Art Review. Safety Science. 2013; 55(0): 207-221. http://dx.doi.org/http://dx.doi.org/10.1016/j.ssci.2012.05.011

[66] Long MH, Bogossian FE, Johnston V. The Prevalence of Work-Related Neck, Shoulder, and Upper Back Musculoskeletal Disorders among Midwives, Nurses, and Physicians: A Systematic Review. Workplace Health and Safety. 2013; 61(5): $223-229$. PMid:23639038 http://dx.doi.org/10.3928/21650799-20130426-38

[67] Daiski I, Richards E. Professionals on the Sidelines: The Working Lives of Bedside Nurses and Elementary Core French Teachers. Gender, Work \& Organization. 2007; 14(3): 210-231. http://dx.doi.org/10.1111/j.1468-0432.2007.00340.x

[68] Pryor J. A Nursing Perspective on the Relationship between Nursing and Allied Health in Inpatient Rehabilitation. Disability and Rehabilitation. 2008; 30(4): 314-322. http://dx.doi.org/doi:10.1080/09638280701256900 